\title{
Design and Analysis of Linear Tapered Slot Antenna for Super High Frequency Applications
}

\author{
Kalaiarasan K, Manikandan T, Nandalal V, Anand Kumar V, Shobana Priya MS
}

\begin{abstract}
In this paper, the proposed LTSA (Linear Tapered Slot Antenna) is assisted with an air cavity and fabricated using LTCC substrate (Low Temperature Cofired Ceramic). The LTSA antennas are widely used in multimedia applications, which require larger bandwidth and high gain. If thelinear slot antenna is designed on low temperature cofiredceramic board, because of its thickness and high dielectric constant, the gain and radiation property is infected critically. By selecting air cavity in the rear end of low temperature cofired ceramic substrate, much gain and good end fire radiation pattern can be acquired. Typically, this antenna has wide bandwidth $(45 \mathrm{GHz}$ to $75 \mathrm{GHz}$ ) and 4.9 to $6.9 \mathrm{~dB}$ gain. The proposed the $3 D$ LTCC modules can be used for wide variety of super high frequency applications.
\end{abstract}

Keywords: MIMO, LTE, Multiplexing, Meander LTSA, Spacing Factor.

\section{INTRODUCTION}

In this modern era, commercial applications of milli-meter wave are short range broadband wireless communication, radars for avoiding automotive collision and LCRN (Local Cellular Radio Network) requires fabrication of low cost, performance of the network is excellent, and elevated plane of incorporation and combination. Many researchers studied LTCC technology for low temperature, which satisfies the above mentioned properties. When designing of these antennas with efficient radiation patterns and high gain, particularly the problem caused in antenna is LTCC material with high dielectric constant. Horn waveguide, Yagi antenna and LTSA (Linear Tapered Slot Antenna) are some of the classification of end fire antennas. Among those types, for a wonderful choice of LTCC design the LTSA is used. LTSA is easy to fabricate, provide broad bandwidth and it is easy for integration. Vivaldi, constant width and exponential are some of the variations of Linear Tapered Slot Antenna, which depends on the antenna aperture shape. All these types aim to enhance beam width property, broad bandwidth, and impedance matching of

Revised Manuscript Received on July 22, 2019.

* Correspondence Author

Kalaiarasan K, Assistant Professor, Department of ECE, Veltech Rangarajan Dr. Sagunthala R\&D Institute of Science and Technology, Chennai, India, Email: kalaiarasan@veltech.edu.in

Manikandan T, Professor, Department of ECE, Rajalakshmi Engineering College, Chennai, Email: manikandan.t@rajalakshmi.edu.in

Nandalal V, Associate Professor, Department of ECE, Sri Krishna College of Engineering and Technology, Coimbatore, India, Email: nandalal@skcet.ac.in

Anand Kumar V, Assistant Professor, Department of ECE, Sri Eshwar College of Engineering, Coimbatore, India, Email:anandkumar.v@sece.ac.in

ShobanaPriya MS, Assistant Professor, Department of ECE, SaveethaSchool of Engineering,Chennai,India, Email:shobanapriyams.sse@ saveetha.com excellent quality. Design of Linear Tapered Slot Antenna and antenna was fabricated using LTCC process is discussed in this paper. Typically, high dielectric on antennas leads to the distorted radiation pattern which reduces the gain. To alleviate this effect, by adopting material modulation technique it is possible to reduce the high dielectric constant in this proposed method or photonic band gap. The use of air cavity will obtain high broadband performance and decrease the dielectric constant.

\section{TYPES OF ANTENNA AND FEEDING METHODS}

A wide variety of antenna has been used in mobile handset they can be split into following categories they are

1. Whip antenna

2. External helical antenna

3. Printed internal helical antenna

4. LTSA(Planar inverted F antenna)

5. L type

6. Patch antenna

7. Ceramic antenna

8. Meander line antenna

9. DPILA(Dual planar inverted L antenna)

Some of the feeding methods used are

1. Coaxial probe feeding

2. Micro strip transmission line

3. Recessed micro strip line

4. Aperture coupling feed

5. Proximity - coupled micro strip line feed

\section{MATERIAL CONSIDERATIONS}

The thin copper foil is used for making the metallic patch. The substrate material provides mechanical support to the elements of radiating patch. Free space wavelength of 0.01 to 0.05 is the thickness of the substrate range. The range of dielectric constant is from 1 to 10 which are divided into 3 groups.

1. Relative permittivity of the substrate is of the range 1.0 to 2.0

2. The substrate having the relative dielectric constant ranging 2.0 to 4.0 . These kinds of material typically made up of Fibre glass shatterproof Teflon.

3. This type of material can be alumina, ceramic or quartz with 4.0 and 10.0 relative dielectric constant.

2 to 3 relative permittivity is used in Teflon based material which is most familiar material. Poly Tetra Fluoro Ethylene (PTEF) is the material having 2 to 3 relative permittivity. It also has a same structure as fiber glass material, which is used in

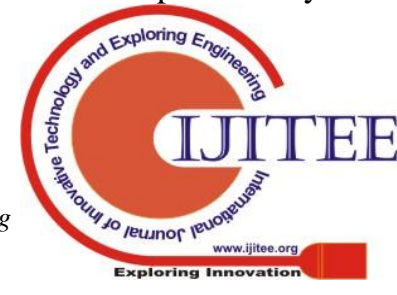


boards executes digital circuits. . For instance, an array of a few elements or a single patch may be fabricated at the L-band frequency on a fiber glass material of low cost, as a 20 0r 30 elements as array at frequency of $30 \mathrm{GHz}$ can go for high cost but result in acceptable loss. The foam panel or dielectric honey comb may be used as a substrate for the large number of array elements to reduced loss, reduce mass of antenna, and reduce the cost of the material whereas having enhanced bandwidth.

\section{PERFORMANCE OF ANTENNA AND ANTENNA DESIGN}

\section{A. Design of LTSA Antenna Element}

The distribution of charge on the plane of antenna is changed in this proposed structure which increases the inductive effect results in reduction of size [4,5]. Meander geometry and elemental position of antenna on the PCB plays a very important role in enhancing the characteristic of the meander LTSA antenna. Fig. 4 shows the measured (dotted curve) return losses and the simulated (solid curve) which show good covenant in the frequency band of $2.2-3 \mathrm{GHz}$. This antenna is operating at the $2.68 \mathrm{GHz}$ which is the centre resonant frequency. The simulated $10 \mathrm{~dB}$ bandwidth $(200 \mathrm{MHz})$ is found to be slightly broader when compared to the measured one $(180 \mathrm{MHz})$.

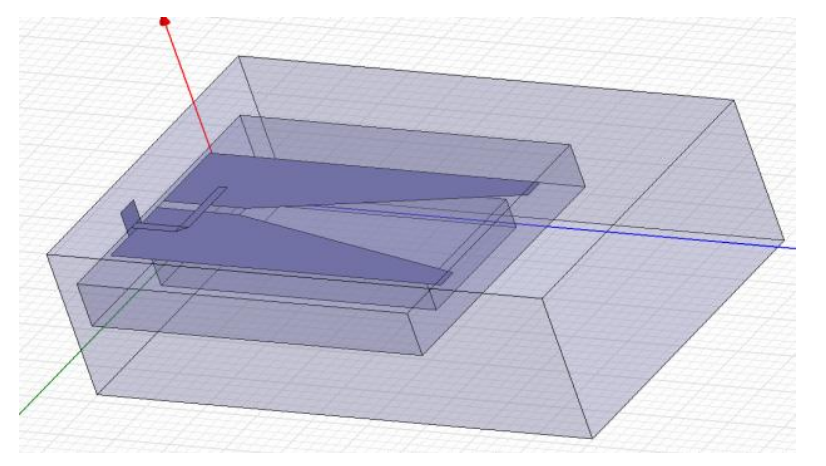

Fig.1. Optimized LTSA antenna element design

\section{B. Double LTSA Antenna Element Design}

Fig. 1 shows the geometry structure of antenna. The dual meander LTSA was constructed with considering of space $6 \mathrm{~mm}$ between the coplanar section and meander coplanar. In $[7,8,9]$ it was signified that dual meander antennas will be having bandwidths of wider range. But dissimilar [10], the planned antenna structure was fabricated on 2 dissimilar planes and therefore the name 3-D. By this method, antenna length is enlarged. The length all meander arm is $11 \mathrm{~mm}$ and the width is $3 \mathrm{~mm}$. The feeding location and the shorting pin was $26 \mathrm{~mm}$ at a distance.

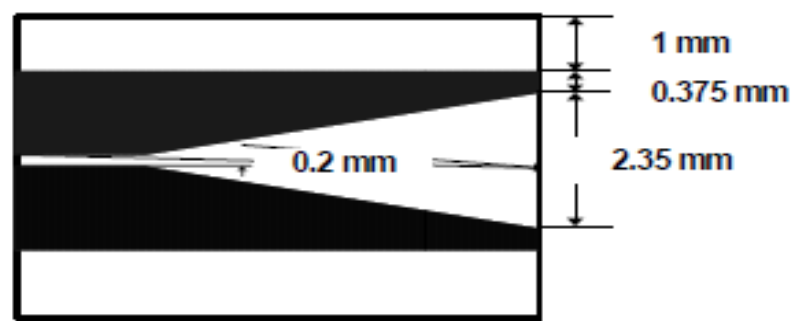

Fig.2.Spatial positioning and dimension of LTSA
On the way to enhance bandwidth, the shorting pin feed was selected as $3 \mathrm{~mm}$ and width of the shorting pin was selected as $0.5 \mathrm{~mm}$. ground plane was $4 \mathrm{~mm}$ away [6] the double meander section was placed. The measurement of the metal box and the ground plane with the spatial positioning and its proportions is shown in Fig. 2.

\section{SPACING OF LTSA ANTENNA AND ITS COUPLING}

The antenna elements and spacing determines and enhances the performance of the MIMO. The various handset configurations are shown in Fig. 3, are differentiated by various antennas orientations and positions on the Printed Circuit Board, and are considered to explore the effect on the performance of MIMO. PT2 is distinguished by 2 meander LTSA elements which are parallel to each other and PT4 is identified by vertical elements based on PT2. PT 8 and PT 6 have less coupling in between the antenna compare with PT2, PT4 and PCB which is due to tiny space between two antennas. Model antenna distinguished by vertical antenna design arrangements, like PT4and PT8 which are intended to illustrate an influence on the cross polarization due to decoupling effect. Near the margin side of the PCB, the antenna elements have the feeding point. Figure 6 exhibits the fabricated structure with the white colour foam which covers the PCB is meant for strengthening the toughness in open air transmission measurement.
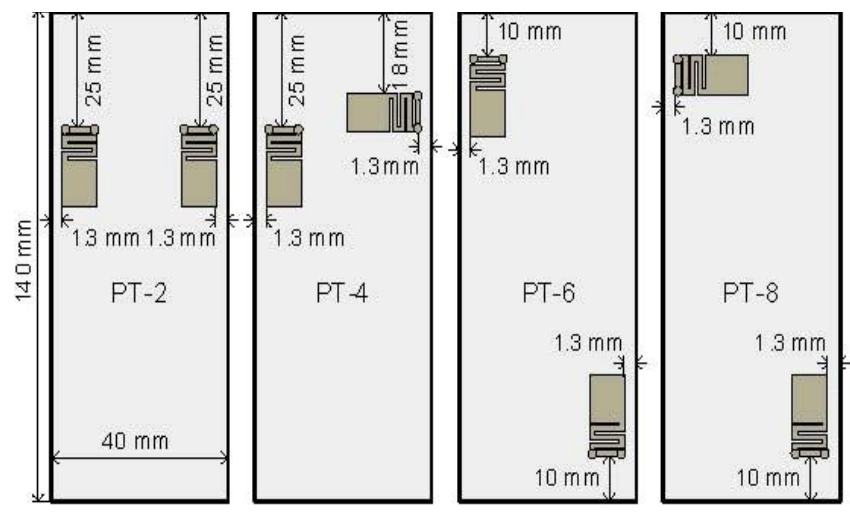

Fig.3. LTSA antenna element spacing

\section{A. Antenna Prototypes Characteristics:}

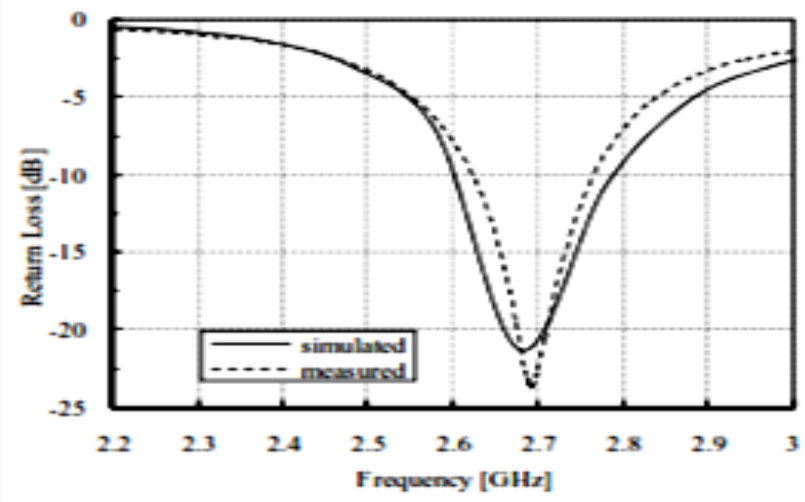

Fig.4. Optimized LTSA Return loss Vs Frequency 
Fig. 4 shows the Prototype simulation and the radiation efficiencies of four prototypes with the measured parameters. PT2, PT4 and PT6 show excellent sign for S-parameters and stimulated results was shown. PT8 has a comparatively huge diversity between measured and stimulated S-parameter due to the deficiency in the fabrication process of smaller antennas. Due to the parallel antenna elements arrangement, PT2 and PT6 exhibit similar radiation. Radiation efficiency of $80 \%$ is achieved by four prototypes but low efficiency is achieved by PT4 due to perpendicular arranged elements.

\section{MEASURED ANTENNA RESULTS AND ANALYSIS}

This is conceivably the motive behind the antennas of wider bandwidth. The existence of the box ensures the antenna to radiate in an omni directionally at the 2 different frequencies and has good quality gain. $1.35 \mathrm{dBi}$ is the peak gain of $700 \mathrm{MHz}$ whereas $1.67 \mathrm{dBi}$ is $960 \mathrm{MHz}$. Figs. 5, 6, and 7 demonstrate the $E \varphi$ and $E 0$ patterns at $850 \mathrm{MHz}$ for $\mathrm{XZ}$ $\left(\varphi=0^{\circ}\right), \mathrm{YZ}\left(\varphi=90^{\circ}\right)$ and XY $\left(\varphi=90^{\circ}\right)$ planes, respectively. The $E 0$ element is just about evenly spread in the $\mathrm{XZ}\left(\varphi=0^{0}\right)$ plane. The $E$ component is constantly below $-25 \mathrm{dBi}$ in that plane. In the XY $\left(\varphi=90^{\circ}\right)$ plane, the positive gain of $E$ from 350X Fig. 5.

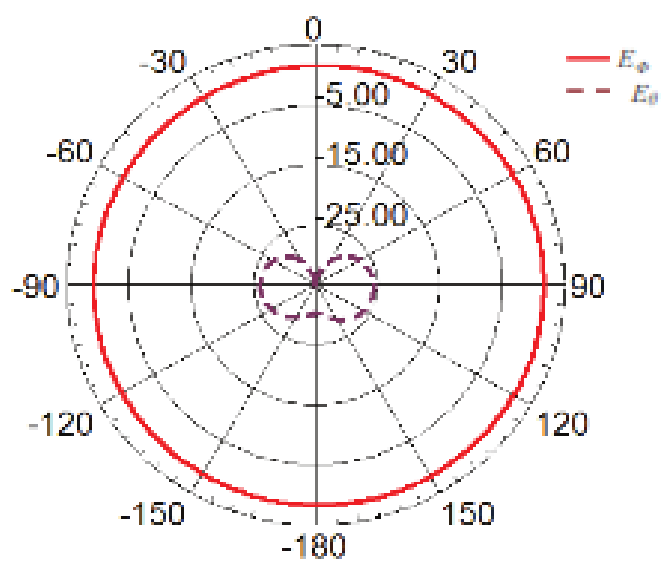

Fig. 5. $850 \mathrm{MHz}$ calculated radiation pattern in the $\mathrm{XZ}$ $\left(\varphi=0^{\circ}\right)$ plane.

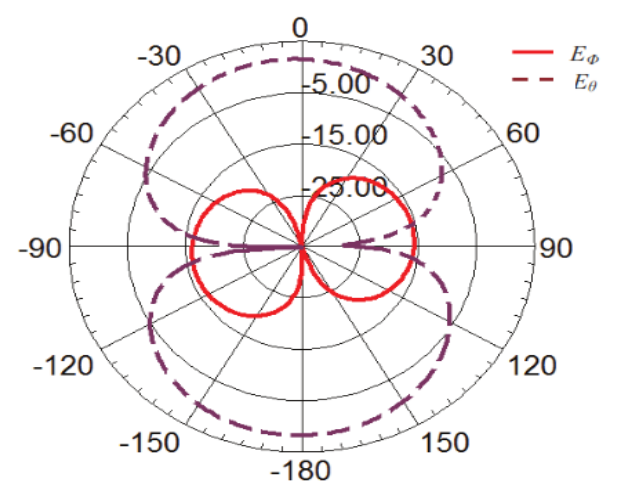

Fig.6. $850 \mathrm{MHz}$ calculated radiation pattern in the $\mathrm{XZ}\left(\varphi=90^{\circ}\right)$ plane.

Calculated radiation pattern at $850 \mathrm{MHz}$ in the $\mathrm{XZ}\left(\varphi=0^{\circ}\right)$ plane. X Fig. 5. Calculated radiation pattern at $850 \mathrm{MHz}$ in the $\mathrm{YZ}\left(\varphi=90^{\circ}\right)$ plane to 310 and from 1690 to 2070 . Two deep notches are obtained roughly 900 and $-900.1 .74 \mathrm{dBi}$ is peak gain obtained in the plane.

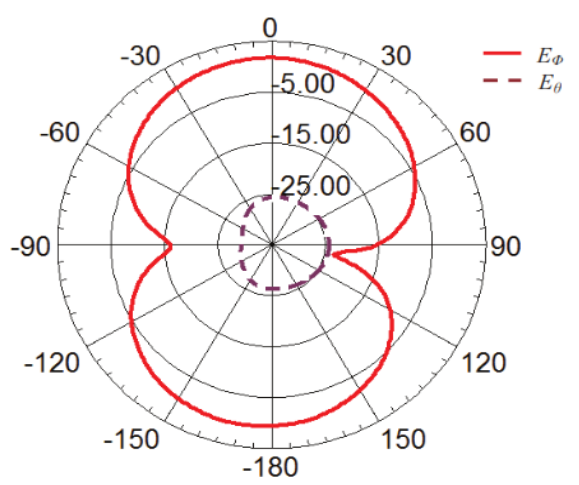

Fig.7. $850 \mathrm{MHz}$ calculated radiation pattern in the $\mathrm{XZ}\left(\varphi=90^{\circ}\right)$ plane.

\section{CONCLUSION}

In this paper, Linear Tapered Slot Antenna (LTSA) was designed with an air cavity and fabricated using LTCC substrate. The LTSA antennas are frequently used in multimedia applications. For the single Meander LTSA the operating frequency is $2.68 \mathrm{GHz}$ and for double meander LTSA its operating frequency is $698 \mathrm{MHz}$ to $960 \mathrm{MHz}$. The experimental results show that, the proposed antenna has acceptable gain and wide radiation patterns at diverse frequencies.

\section{REFERENCES}

1. A. Hottinen, O. Tirkkonen, and R. Wichman, Multi-antenna Transceiver Techniques for $3 \mathrm{G}$ and Beyond, Wiley, West Sussex, England, 2003

2. G.J. Foschini, and M. J. Gans, "On limits of wireless communications in a fading environment when using multiple antennas," Wireless Personal Commun., Vol. 6, 311-335, 1998.

3. 3GPP TS 36.101, V8.3.0, "EUTRA User Equipment Radio Transmissionand Reception," September 2008.

4. L. Zheng, X. Zhang and S. Lai, "Resonant Characteristics of the Meander-line Dipole Antenna," Journal of Microwaves, vol. 3, 2006.

5. V.Nandalal, V.Anand Kumar and Manikandan.T, "Performance Evolution of Reconfigurable Antenna Using Contact and Non-Contact Feeding Technique", in Proceedings of the Third International Conference on Electronics Communication and Aerospace Technology [ICECA 2019] IEEE Conference Record \# 45616; IEEE Xplore ISBN: 978-1-7281-0167-5, pp. 952-954, 2019.

6. M. Ali, S. S. Stuchly, and K. Caputa, "A wide-band dual meander sleeve antenna," J. Electromagn. Waves Applicat.,vol. 10, no. 9, pp. 1223-1236, 1996.

7. M. Ali, G. J. Hayes, H.-S. Hwang, and R. A. Sadler, "Design of a multiband internal antenna for third generation mobile phone handsets," IEEE Trans. Antennas Propagat., vol. 51, pp. 1452-1461, July 2003.

8. Manikandan. T, Kanagavalli. R, Kavitha. B, Mutharasi. J, Sathish.M, "Design and development of Patch Antenna Array with Band-pass Filter for ISM Band Applications", in Proceedings of the Third International Conference on Electronics Communication and Aerospace Technology [ICECA 2019] IEEE Conference Record \# 45616; IEEE Xplore ISBN: 978-1-7281-0167-5, pp.888-891, 2019.

9. RadhouaneLaajimi and Ali Ajmi, "Design of Higher performance Low power Microstrip Patch Antenna with uniform supply used for UMTS Applications", Int. Conf. Control, Decision and Information Technologies, Apr. 2016.

10. Hang Wong, Kwok Kan So, Xia Gao, "Bandwidth Enhancement of a Monopolar Patch antenna with V-shaped slot for car to car and WLAN communications", IEEE Trans. Vehicular Technology, vol.65, No. 3, Mar. 2016. 


\section{AUTHORS PROFILE}

Mr. Kalaiarasan received his B.E. (Electronics and Communication Engineering) in Anna University, Chennai, India and M.E. (Communication Systems) in Anna University, Chennai, India. Currently he is working as an Assistant Professor in Veltech Rangarajan Dr. Sagunthala R\&D Institute of Science and Technology, Chennai, India and worked as an Instrumentation Engineer in Chennai Petroleum Corporation Limited, Chennai, India in his initial career. He has twelve Scopus Indexed Journals to his credit. His current research interests include Wireless Communication, Antenna and Wave Propagation, and RF and Microwave Engineering. He is a reviewer for reputed Engineering journals and he is a Professional member of IAENG and IRED.

Dr. T. Manikandan is a Professor working at Rajalakshmi Engineering College, Thandalam, Chennai. $\mathrm{He}$ has completed his Ph.D titled " A study on computer-aided diagnosis systems for lung cancer detection and its three dimensional visualization using machine learning techniques" at Anna University, Chennai during January, 2017. He did his bachelor's degree in Engineering from Vellore Engineering College, Chennai under Madras University \& master's degree in Engineering from College of Engineering, Anna University, Guindy, Chennai during 1998 \& 2007, respectively. He is having 21 years of teaching experience which includes both UG and PG. He also guided many projects at UG \& PG levels. He has 50 papers in refereed international journals and conferences in his credit. He is serving as editorial board member for various international journals such as International journal of Biomedical and Healthcare Sciences, Archives of General Internal Medicine, Journal of Cancer Diagnosis, Journal of Medical and Clinical Oncology, Journal of Clinical Epigenetics and Integrative Cancer Biology and Research.

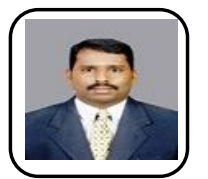

Dr.V.Nandalal received his B.E.(Electronics and Communication Engineering) in University of Madras, Chennai, India and M.E.(Communication Systems) in Anna University, Chennai, India., and Ph.D.(Information and Communication Engineering) in Anna University, Chennai, India. Currently he is working as an Associate Professor in Sri Krishna College of Engineering and Technology, Coimbatore, India. His current research interests include Wireless Communication, Antenna and Wave Propagation, Advanced Microwave Circuit and Systems. He is a Professional member of IEEE, IEICE.

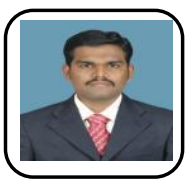

Mr. V. Anand Kumar is currently working as Assistant Professor in Department of ECE in Sri Eshwar College of Engineering, Coimbatore. He is pursing PhD in Anna University Chennai. He received M.E Degree in Applied Electronics from SSN, Anna University Chennai in 2010. He received the B.E degree in Electronics and Communication Engineering from JCET, Anna University Chennai, in 2008 His primary research interests include VLSI Signal Processing, FPGA implementation, channel coding. He is a Professional member of ISTE.

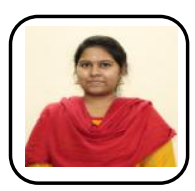

Mrs. M S. Shobana Priya is a Assistant Professor working at Saveetha School of Engineering, Thandalam, Chennai. She is currently pursuing her Ph.D in Machine learning at Saveetha School of Engineering, SIMATS, Thandalam since June, 2018. She did her bachelor's degree in Engineering from Jaya Engineering College, Thiruniravur under Anna University \& master's degree in Engineering from College of Engineering, Anna University, Guindy during 2011 \& 2015, respectively. She is having 1.5 years of teaching experience in UG. She also guided many projects at UG levels. 